The Lahore Journal of Economics

$10: 1$ (Summer 2005) pp. 65-81

\title{
Determinants of Poverty in Pakistan: A Multinomial Logit Approach
}

\section{Umer Khalid, Lubna Shahnaz and Hajira Bibi*}

\section{Introduction}

According to the World Development Report 2000-2001 almost half of the world's population -2.8 billion out of 6 billion live on less than $\$ 2$ a day; while a fifth, i.e., 1.2 billion live on less than $\$ 1$ a day with 44 per cent of them living in South Asia. ${ }^{1}$ The Pakistan Economic Survey 2000-2001 reports that about 33 per cent of the country's population is living below the food poverty line. ${ }^{2}$ Food poverty trends since 1990-91 shows that food poverty has been on the rise since 1990-91, with a higher increase being observed in rural areas where food poverty increased from a low of 22.5 per cent in $1992-93$ to a high of 34.8 per cent in 1998-99 (Table-1).

In Pakistan, a large share of the household budget is spent on food. Approximately half of the household consumption expenditure is used to meet the nutritional requirements of the household at the national level. In rural areas this proportion is about 54 per cent, while in urban areas it is 41 per cent $^{3}$ (see Appendix Table-1). Despite such high proportions of consumption expenditure on food, the incidence of food poverty remained high, about one-third of households were living below the food poverty line and were not meeting their nutritional requirements.

\footnotetext{
* The authors are Strategic Planning Officer, at State Bank of Pakistan, Karachi, Senior Research Officer at Centre for Research on Poverty Reduction and Income Distribution (CRPRID) and Lecturer at International Islamic University, Islamabad respectively.

${ }^{1}$ South Asia accounts for 22 per cent of the global population.

${ }^{2}$ Poverty is more than meager physical deprivation of goods and services. It has social and psychological effects that prevent people from realizing their own potential. The incidence of poverty is generally defined as the proportion of the population that does not have enough income to purchase a reference food bundle yielding a specified amount of calories per day and to provide for a modest allowance for non-food commodities and services.

${ }^{3}$ According to the Pakistan Socio Economic Survey (PSES) 1998-99.
} 
Poverty is closely associated with malnutrition, as previous studies have shown. Ahmed and Ludlow (1989), Mahmod et al. (1991) and Havinga et al. (1989) mention low purchasing power of money, larger household size, lower level of education, large number of dependents, age of head of household, etc as determinants of poverty.

In a more recent study, Qureshi and Arif (2001) explained the determinants of poverty by using logistic regressions. Two models were estimated, one for the determinants of food poverty and the other for determinants based on the basic needs approach. The study used the 1998-99 Pakistan Socio Economic Survey (PSES) data set. They found that the larger household pushes the family towards poverty. Similarly educational attainment is a critical determinant of the incidence of poverty and should be given importance in the designing and implementation of poverty alleviation programs. An increase in the level of schooling of one individual not only has an impact on that individual's productivity and hence earnings, but may also influence the productivity and earnings of others with whom that individual interacts. Landlessness in rural areas is likely to be associated with poverty. Provision of employment in rural areas may reduce the risk of poverty. In short, the study concluded that policy-influenced variables such as schooling and employment creation are important factors that can lead to a significant reduction in poverty levels.

The objective of this paper is to examine the incidence of food poverty in Pakistan at the national level and to further see its decomposition at the urban and rural level, as well as to identify its key determinants. The paper also attempts to identify the key determinants of food poverty; factors which push people to live in the food poverty situation. The impact of loans, credit and financial assets on food poverty will also be analyzed by using the multinomial logit approach which has not been attempted previously. The results achieved by our model should have an important bearing on future policy-making regarding food poverty in Pakistan. The paper is divided into 4 sections. Section 1 is the introduction while section 2 explains the methodology and the model used in our analysis. Section 3 presents data and results of the model, while section 4 concludes the paper. 
Table-1: Trends in incidence of food poverty (\%)

\begin{tabular}{lccc}
\hline Year & Pakistan & Rural & Urban \\
\hline $1990-91$ & 23.3 & 26.2 & 18.2 \\
$1992-93$ & 20.3 & 22.5 & 16.8 \\
$1993-94$ & 23.6 & 26.3 & 19.4 \\
$1998-99$ & 32.6 & 34.8 & 25.9 \\
\hline
\end{tabular}

Source: Jafri (1999) “Assessing Poverty in Pakistan" Mahbub u1 Haq Human Development Centre and PIDE 1998-99 PSES primary data.

\section{Methodology}

The analysis in this paper is based on micro data taken from the 1998-99 round of the merged Household Integrated Economic Survey (HIES) and Pakistan Integrated Household Survey (PIHS), conducted by the Federal Bureau of Statistics, Government of Pakistan. These surveys provide a wide range of information at the household level such as information on household income, expenditure, employment, migration status, marriage and maternity history, transfers received and paid out, assets and liabilities. The total sample considered here comprises 14,518 households, out of which 9,048 are rural households and 5,470 are urban households.

To determine the incidence of poverty, three elements are needed: an indicator of well being or welfare (e.g. per capita caloric intake; per capita expenditure on food); a normative threshold representing the well being an individual (or household) must attain to be above poverty (e.g. a poverty line); and an aggregate measure to assess poverty across the population (e.g. head count ratio).

To explore the determinants of food poverty three multinomial logit regression models are estimated on the basis of three mutually exclusive categories of poor, non-poor and very poor households. One model is estimated overall for Pakistan and the remaining two for its rural and urban areas.

\section{Measurement of Poverty}

The per capita expenditure on food is used as an indicator of welfare in this paper. Poverty lines are generally drawn in absolute and/or relative terms. Relative poverty refers to the position of an individual or household 
in relation to a specific poverty line. This study uses absolute food poverty lines estimated by Qureshi and Arif (2001) that are based on the estimated cost of food consistent with a calorie intake of 2550 per adult equivalent per day for rural areas. A daily intake of 2995 calories per adult equivalent is considered for urban areas. ${ }^{4}$ At the national level the food poverty line is Rs. 361.74 per capita per month, while at the regional level per capita per month poverty lines are Rs. 353.73 and Rs. 378.77 for rural and urban areas, respectively. In this analysis the headcount ratio, i.e. proportion of poor households among total households, is used as a measure of poverty.

\section{The Model}

To examine the determinants of food poverty we carry out a multivariate analysis. Three separate models are estimated. Model 1 focuses on the determinants of food poverty at the overall level, while model 2 and 3 analyze these determinants at the regional level. Our dependent variable in each model is categorized into three mutually exclusive categories. We assume that a typical household belongs to one of three mutually exclusive categories. These categories are (i) poor (ii) non poor and (iii) very poor. We categorize these alternatives as 1, 2 and 3, respectively. Non poor households are those whose per capita per month expenditure on food is above the poverty line, while poor households have per capita per month expenditure on food below the poverty line. Very poor households comprise those households whose per capita per month food expenditure is less than 50 per cent of the poverty line.

Assuming that the errors in each model are independently and identically distributed with Weibull distribution, then the difference between the errors has a logistic distribution [Green (1992)] and multinomial logit is the appropriate technique of estimation. The probabilities in multinomial logit model are therefore given by

$$
\begin{aligned}
& \operatorname{Prob}(Y=j)=\frac{e^{\beta_{j} x_{i}}}{1+\sum_{k=1}^{J} e^{\beta^{\prime} x_{i}}} \\
& \operatorname{Prob}(Y=0)=\frac{1}{1+\sum_{k=1}^{J} e^{\beta^{\prime} x_{i}}} \quad \text { for } j=1,2,3 \quad \ldots \quad \ldots \ldots
\end{aligned}
$$

\footnotetext{
${ }^{4}$ For details see Qureshi and Arif (2001)
} 
where coefficients $\beta$ s are normalized to zero and $\mathbf{x}$ is the vector of explanatory variables. The multinomial logit model is identified by normalizing the coefficient of one of the categories to zero. Hence we normalize the coefficient of the alternative of poor to zero.

The coefficients in our models are difficult to interpret because they only provide information on the effects of independent variables on the odds ratio. To interpret the effects of independent variables $(x)$ on the probability of each category of poverty we calculate partial derivatives as below.

$$
\frac{\partial P}{\partial X}=P_{j}\left(1-P_{j}\right) \beta_{x j}-\sum_{k} P_{j} P_{k} \beta_{x k} \quad \text { where } j, k=1,2,3 \quad \ldots \ldots \quad \text {. (2) }
$$

where $P$ is the probability of being a member of each alternative. The $\log$ of likelihood function is defined by defining for each household $d_{i j}=1$ if alternative category $j$ is chosen for household $i$, and 0 if not, for the other possible outcomes. Then for each household $i$, one and only one of $d_{i j}$ 's is one [Green (1992)]. The log likelihood function is given by

$$
\ln L=\sum_{i} \sum_{j} d_{i j} \ln \operatorname{Pr} o b\left(Y_{i}=j\right)
$$

Our models are based on the assumption that the three alternatives available for the poverty status of a household are independent of each other. It is also assumed that for each household all three options are simultaneously open. The parameters for each category of poverty in each model are obtained from the estimation of a single maximum likelihood logit.

\section{Measuring Independent Variable}

There may be a number of demographic, economic and social factors that can cause a household to be non-poor, poor or very poor. The demographic characteristics include age of the household head, sex of the household head, household size and family type. Age of the head of household is measured in complete years. The sex of household head takes a value of one if the head is female and zero if the head is male. The family type is entered into the model as a dummy variable, taking the value of one if the family is nuclear and zero otherwise.

The social indicator of education is included in our framework of analysis. Education or literacy is an indicator of quality of life in its own right as well as a key determinant of the poor's ability to take advantage of income-earning opportunities. Four levels of educational attainment are 
represented by three dummy variables. The first variable takes the value of one if the head of household is educated to the primary level and zero otherwise. The second variable represents the middle level, and coded one if the head is in this category and is zero otherwise. The third variable takes the value of one if the head of household is educated to matriculation or higher level and zero otherwise.

Two economic indicators i.e., farm status and household properties are also analyzed. The farm status of the head of household is measured by a dichotomous variable taking the value of one if the occupation of the head of household is agriculture and zero otherwise. Only two types of household assets are considered, its tangible asset of land and its total financial assets (including liquid assets, savings and other). The total financial assets are measured in nominal terms and the variable of land is a dummy variable taking the value of one if land is owned by the household and is zero otherwise.

Two other indicators included in the study are migration status and amount of loans and credit taken by the head of household. The migration status is measured by a dichotomous variable taking the value of one for migrant ${ }^{5}$. Total loan and credit of the household are taken in rupees.

\section{Data \& Descriptive Analysis}

The summary statistics of variables used appear in Table 2 . It shows that the average age of the head of household is 45 years among the three categories of non-poor, poor and very poor households at the national as well as the rural and urban level.

At the national as well as the regional level, the proportion of female heads of household is slightly high in the non-poor category at 8 per cent as compared to 5 per cent in the poor and very poor households. In general, estimates indicate that the proportion of female heads of household is very low as compared to male heads. This is quite understandable in a society where a woman can not be considered the head of household, unless she is a widow or divorced, living or is being forced to live on her own means.

At the overall rural and urban level, the proportion of nuclear families is highest in the non-poor group - almost 62 per cent, while in poor households it is approximately 55 per cent. Almost half of the very poor households at all three levels of analysis are from non-nuclear families.

${ }^{5}$ Migrant is defined as a person who changes his place of residence from one district to another. 
In general, very poor households are less educated and due to their traditional beliefs prefer to live in joint families.

Regarding household size our summary statistics indicate that the household size is relatively smaller in non-poor households and larger in poor and very poor households. Further household size is large in rural areas as compared to urban areas.

Our statistics indicate that more than two-third households in the very poor category are illiterate at the national as well as the regional level. In urban areas, only 18 per cent of non-poor households have completed at least ten years of schooling, while this ratio is 15 per cent in rural areas. This ratio is very low in the case of poor and very poor households. Certain demand and supply side factors are responsible for this outcome together with social and cultural practices and traditions. Low human capital investment by households is mainly due to the lack of economic opportunities, parents' education, high dependency ratio, lack of accurate information to facilitate efficient schooling decision by parents especially in remote rural areas, high gender gap in earnings, lack of protective environment especially for girls and social and political culture in the country [See also Sawada (1997)]. In rural areas literacy is still lower because of lack of schools in remote rural areas. Moreover schools in rural areas have fewer facilities, lower quality of teaching materials, high teacher absenteeism and many of them exist only on paper (ghost schools).

As concerns farm status, the summary statistics indicate that among non-poor households the proportion of farm households is larger than their counterparts - non-farm households, both at national and regional levels of analysis. Moreover, results indicate that in urban areas among poor and very poor households, the proportion of farm households ${ }^{6}$ is larger than nonfarm households; this may be the result of rural to urban migration because there are less jobs for such migrants in urban areas.

In case of household property, the results indicate that among poor and very poor households only a small proportion has land holdings. Moreover, the average amount of total financial assets of the poor households is very low as compared to non-poor households. This is an expected outcome as the poor are mostly less educated, engaged in low paid jobs and having large families and thus less likely to have the ability to purchase land and other financial assets.

\footnotetext{
${ }^{6}$ For further detail see HIES (1998-99), Questionnaire: Section 9-M-Part-A
} 
The average amount of loans and credit is slightly higher for poor households as compared to non-poor households but is very low for very poor households. Many studies have shown that the poor are disadvantaged in terms of access to credit because of the lack of collateral [Kazi and Raza (1995)]. Access of women to credit is further constrained by limited mobility, illiteracy and most importantly the lack of assets for collateral. Although legally women have the right to ownership of land but due to weak implementation, mostly women cannot get access.

\section{Results from Multinomial Logit Model}

Table-3 shows the incidence of food poverty at the national and regional levels. It can be seen that at the national level, 33 per cent of the households are poor, while 8 per cent of the households are very poor i.e., their per capita per month food expenditure is less than 50 per cent of the poverty line of Rs. 361.74. The results show that more than one third of the sampled households were living below the food poverty line in 1998-99.

Table-3: Incidence of Food Poverty by rural and urban areas

\begin{tabular}{lccc}
\hline Households & Pakistan & Rural & Urban \\
\hline Poor & 32.5 & 36.6 & 30.7 \\
Very Poor & 7.5 & 9.2 & 10.5 \\
\hline
\end{tabular}

Regarding the incidence of food poverty in rural and urban areas, the results indicate that 37 per cent of rural households and 31 per cent of urban households lie in the category of poor, while 9 per cent of rural households and 11 per cent of urban households lie in the category of very poor. These results suggest that food poverty is slightly higher in rural areas, 46 per cent as compared to urban areas 41 per cent.

The estimation results from the multinomial logit model are presented in Table 4. The estimated parameters for each category, i. e., poor, very poor and non poor are obtained from a single maximum likelihood multinomial logit estimation. Table 4 reports partial derivatives at the mean of the dependent variable in bold letters followed by the logit coefficients, while t-statistics are reported in parentheses.

The results indicate that the age of head of household reduces the probability of the household being poor or very poor and increases the probability of the household being non-poor. This effect is statistically significant at the overall rural and urban level and is consistent with the 
studies of Qureshi and Arif (2001) and Kemal et al. (2001). This indicates that with increase in age of head of household, his income and hence consumption increases which in turn reduces the probability of poverty.

It is evident from our results that at both the national and regional level, the sex of head of household has a significant positive effect on the probability of non-poor category and has a negative effect on the remaining two alternatives. This negative effect is insignificant for the very poor category. In general female heads spend more on the nutrition, health and welfare of the children while due to cultural and social norms males spend more on land, housing, traveling and smoking [SPDC (1997)].

Regarding the effect of household size, at the overall level our estimates indicate that with an increase in household size a household is 4 per cent less likely to be non-poor, 3 per cent more likely to be poor and 1 per cent more likely to be very poor. At the regional level, results also indicate that a household is more likely to be poor if it has a larger number of members. This result is consistent with earlier studies [e.g. Qureshi and Arif (2001) and Kemal et al. (2001)]

At the regional level, family type has no significant effects, while at the national level nuclear families are more likely to be non-poor. As already mentioned in nuclear families due to lower dependency ratio, less time requirement for other household activities, women can spare more time to participate in earning activities, especially with their male siblings.

Schooling of head of the household has a significant effect on poverty, both at the national as well as at the regional level. At the national level, a household whose head has at least 10 years of schooling is 27 per cent more likely to be non-poor, 16 per cent less likely to be poor and 11 per cent less likely to be very poor. At the rural and urban level, results also indicate that the higher the level of education the more likely the household is to be out of poverty. Education is a critical input into economic development and the externalities arising out of high literacy rate far exceed the benefits to the individual from attaining education. Thus developing human capabilities by imparting education is important not only in its own right but also important for overall economic growth which, in turn, can lessen poverty and increase the empowerment of disadvantaged groups. Not only this, education also enables people to take advantage of better job opportunities, induces people to have better health and helps in reducing the mortality rate and fertility rate [See Behrman (1995)]. 
Table-4 further shows that at the national level, farm households as compared to non farm households are 3 per cent more likely to be nonpoor, 2 per cent less likely to be poor and very poor. This shows that farm households are more likely to be non-poor in terms of food poverty. This result is consistent with Qureshi and Arif (2001). The results at the regional level are similar.

Household assets of land and total financial assets have a significant effect on poverty. Results indicate that the possession of land or financial assets increases the likelihood of being non- poor and reduces the likelihood of being poor and very poor. Combining the effect of these assets and the effect of literacy the results indicate that human, physical and financial assets that poor people possess have a potent effect on their prospects for escaping poverty because their assets can enable poor people to take advantage of opportunities such as jobs, credit, public services, school and health services.

The effect of migration is significant only at the overall level indicating that migrated households are 4 per cent more likely to be nonpoor and 2 per cent less likely to be very poor as compared to the nonmigrated households. Migration has probably provided them with an opportunity to move out of poverty.

Regarding the effect of loan and credit at the overall leve1, results indicate that the availability of loans helps the poor to come out of poverty. At the rural-urban level loans and credit have a negative and significant effect on the very poor category.

\section{Conclusion}

The present study examines the incidence and determinants of food poverty in Pakistan. Our results indicate that on average 40 per cent of households are poor at the national level. In rural areas, poverty is comparatively higher with 46 per cent of the households falling below the poverty line, while in urban areas 41 per cent of households are poor. Among these poor households, 8 per cent of the households at the national, 9 per cent at the rural and 11 per cent at the urban level fall into the category of very poor having per capita per month food expenditure of less than 50 per cent of their respective poverty lines.

Our analysis further indicates that the age of the head of household is an important determinant of food poverty. Where age of the head of household is high, the household is more likely to be non-poor. Moreover, 
large household size, lack of human assets such as education and skills, lack of other assets such as land and financial assets and lack of credit appear to be the main causes of poverty. Our estimates also indicate that non-nuclear families are more likely to be poor. We find that although there is a very low proportion of households with female heads but households with female heads are more likely to be non-poor. Moreover, migrated and farm households are likely to be less poor in terms of food poverty.

These results indicate that poverty reduction efforts should be geared towards expanding the assets of poor people so that their position and control over their lives can be strengthened. One cross-country study [Klasen (1999)] indicates that countries that invest in girls' education have a high rate of economic growth. Accumulation of physical and financial assets by the poor can be improved by taking action on three fronts. First, public spending on basic social and economic services should be increased. Secondly, public service delivery systems should be reformed to ensure good quality of service delivery. Thirdly, poor communities and households should be able to participate in the planning and monitoring of public services to keep the service providers accountable.

Easy access to and availability of credit is essential to enable the poor household to start some income earning activities such as shopkeeping, opening of public call offices and stitching schools, crockery and cutlery business, etc. Easy access to loans and credit can be made possible through micro credit schemes where small loans can be given out on the basis of group guarantees without requiring any collateral. 


\section{APPENDIX}

Table-1: Distribution of Monthly Household Consumption Expenditure 1998-99 (\%)

\begin{tabular}{lccc}
\hline & Pakistan & Rural & Urban \\
\hline Food & 48.0 & 53.8 & 41.4 \\
Clothing and Personal Care & 11.0 & 11.5 & 10.5 \\
Housing & 21.3 & 16.8 & 26.3 \\
Health & 3.3 & 3.7 & 2.9 \\
Education & 2.0 & 1.4 & 2.9 \\
Transportation & 3.7 & 3.0 & 4.4 \\
Other (Marriage and Recreation) & 10.7 & 9.8 & 11.6 \\
All & 100 & 100 & 100 \\
Average Monthly Household & 6546 & 5387 & 8964 \\
Expenditure (Rs.) & & & \\
\hline
\end{tabular}

Source: PIDE's 1998-99 PSES primary data 


\section{References}

Ahmed, E. and S. Ludlow, 1989 "Poverty, Inequality and Growth in Pakistan.” Pakistan Development Review 28: 4 Part II.

Behrman, J. R., 1995, "Pakistan: Human Resource Development and Economic Growth into the Next Century.” Background Paper for Pakistan 2010, Washington: The World Bank.

Ercelawn, A., 1989 "Poverty in Pakistan: Choice of Poverty Criteria”. Draft Paper.

Government of Pakistan, 2001, Pakistan Integrated Household Survey 199899. Federal Bureau of Statistics.

Government of Pakistan, 2001, Household Integrated Economic Survey 1998-99. Federal Bureau of Statistics.

Green, W. H. (1992), Econometric Analysis. Second Edition, New York: Macmillan Publishing Company, August.

Havinga, I. C.; Haanappe1, F.W. Louter, A.S and van den Ande1 W.A., 1989 "Poverty in Pakistan 1984-85." Pakistan Development Review, 28: 4 Part II.

Jafri, S. M. Younis, 1999 “Assessing Poverty in Pakistan.” In A Profile of Poverty in Pakistan. Islamabad: Mahbub ul Centre of Human Development.

Kazi, Shahnaz and Bilquees Raza, 1995 "Rural Women's Access to Credit and Extension: Strategy for Change" Pakistan Development Review, 34: 4 Part II PP.753-65.

Kemal, A. R; M. Irfan and G.M. Arif, 2001 "MIMAP Synthesis Report: Major Conclusions and Policy Implications" MIMAP Technical Papers Series No. 3. Pakistan Institute of Development Economics, Islamabad, Pakistan.

Mahmod, S., Shiekh, K.H. and Mahmod, T., 1991 "Food Poverty and its Causes in Pakistan” Pakistan Development Review, 30:4. 
Qureshi, S. K and G.M. Arif, 2001, Profile of Poverty Pakistan, 1998-99. MIMAP Technical Paper Series No. 5. Pakistan Institute of Development Economics, Islamabad, Pakistan.

Sawada, Y., 1997 "Human Capital Investment in Pakistan: Implications of Micro-Evidence from Rural Villages.” Paper Presented at Thirteen Annual General Meeting of Pakistan Society of Development Economists.

SPDC, 1997 "Review of Social Action Program". Social Policy and Development Centre, Research Report,

World Bank, 2000, World Development Report 2000-2001. Washington DC 